\title{
Studies on the Natural History of Asymptomatic Diabetes in Young People
}

\author{
By Stefan S. Fajans, John C. Floyd, Sumer Pek, and Jerome W. Conn
}

Forty-five young patients with chemical diabetes have been followed for 1-16 yr. Among 21 of them aged 9-17 $\mathrm{yr}, 4$ have developed insulin-dependent diabetes mellitus. None of the 24 aged 18-25 yr have decompensated. Delayed and subnormal insulin response to oral glucose was noted in those with chemical diabetes compared to normals, except for one nonobese patient who had hyperinsulinemia. Consider- able fluctuation in glucose and/or insulin responses and their relationship was noted in repeated testing. These observations emphasize that validation of diagnostic criteria for glucose tolerance test interpretation need not depend on a high rate of progression to more severe hyperglycemia, and that the slow progression of latent diabetes permits consideration of prophylactic measures.

$I^{T}$

$T$ IS WELL RECOGNIZED that the carbohydrate intolerance of latent or chemical diabetes in middle age may show little or no progression in severity over many years. On the other hand, it has generally been assumed that diabetes in children and adolescents can rarely be recognized at an early stage, since the first symptoms of overt diabetes are frequently of sudden and exposive onset. ${ }^{1}$ It has also been reported that the course of diabetes in the young is characterized by a rapid and progressive decrease in insulin reserves. ${ }^{2}$ Since 1960, we have reported that asymptomatic, latent, or "chemical" diabetes can be recognized in children and young adults by the finding of abnormal carbohydrate tolerance, and that such patients may exhibit the nonprogressive course of the carbohydrate intolerance of "maturity onset-type" of diabetes. ${ }^{3-7}$ Since 1966, at least eight other reports have appeared, which also indicate that asymptomatic diabetes can be discovered in young people by the use of the glucose tolerance test. ${ }^{8-15}$

From the Department of Internal Medicine, (Division of Endocrinology and Metabolism and the Metabolism Research Unit), The University of Michigan, Ann Arbor, Mich.

Presented at the Conference on Chemical Diabetes Mellitus in Childhood, Ponte Vedra Beach, Florida, December 5-6, 1970.

Received for publication April, 1972.

Supported in part by USPHS Grants AM-00888, AM-02244, and T1-AM05001; National Institutes of Arthritis and Metabolic Diseases; and by grants from the Upjohn Co., Kalamazoo, Mich.; Pfizer, Inc., New York; and the Research Foundation of the American Diabetes Association.

A portion of this paper was presented at the Seventh Pan American Congress of Endocrinology, Sao Paulo, Brazil, August 21, 1970.24

Stefan S. Fajans, M.D.: Professor of Internal Medicine, Department of Internal Medicine, University of Michigan, Ann Arbor, Mich. John C. Floyd, Jr., M.D.: Professor of Internal Medicine, Department of Internal Medicine, University of Michigan, Ann Arbor, Mich. Sumer Pek, M.D.: Assistant Professor of Internal Medicine, Department of Internal Medicine, University of Michigan, Ann Arbor, Mich. Jerome W. Conn, M.D.: Professor of Internal Medicine, Department of Internal Medicine, University of Michigan, Ann Arbor, Mich. 
Table 1. Mild Diabetes of Young People

\begin{tabular}{|c|c|c|c|}
\hline & $\begin{array}{l}\text { Patients } \\
\text { Age 9-17 }\end{array}$ & $\begin{array}{l}\text { Patients } \\
\text { Age 18-25 }\end{array}$ & $\begin{array}{l}\text { Control Subjects } \\
\text { Age } 18-25\end{array}$ \\
\hline Number of subjects & 21 & 24 & 48 \\
\hline Mean age & 12.9 & 22.1 & 21.6 \\
\hline FBS $<99 \mathrm{mg} / 100 \mathrm{ml}$ & $13^{*}$ & $16 \ddagger$ & 48 \\
\hline FBS $100-120 \mathrm{mg} / 100 \mathrm{ml}$ & $5 \dagger$ & 5 & 0 \\
\hline $\mathrm{FBS}>120 \mathrm{mg} \%$ & 3 & 3 & 0 \\
\hline $\begin{array}{l}\text { Blood glucose-sum of } \\
\text { increments } \mathrm{mg} / 100 \mathrm{ml}\end{array}$ & $619 \pm 53$ & $521 \pm 38$ & $130 \pm 10$ \\
\hline $\begin{array}{l}\text { Plasma insulin-sum of } \\
\text { increments } \mu \mathrm{U} / \mathrm{ml} \\
\text { (nonobese subjects) }\end{array}$ & $167 \pm 31(14)$ & $\begin{array}{c}214 \pm 34(13) \\
1175\end{array}$ & $467 \pm 47$ \\
\hline Obese & 3 & 5 & 0 \\
\hline $\begin{array}{l}\text { Yr of follow-up } \\
\text { Mean }\end{array}$ & $\begin{array}{c}1-15.8(17 \mathrm{pts}) \\
7.6\end{array}$ & $\begin{array}{c}1-13(18 \mathrm{pts}) \\
6.3\end{array}$ & \\
\hline $\begin{array}{l}\text { Progression to insulin- } \\
\text { dependent diabetes }\end{array}$ & 4 & 0 & 0 \\
\hline $\begin{array}{l}\text { Age at diagnosis } \\
\text { Initial FBS }\end{array}$ & $\begin{array}{c}11 \mathrm{yr}, 14 \mathrm{yr}, 11 \mathrm{yr}, 17 \mathrm{yr} \\
125 \mathrm{mg} / 100 \mathrm{ml}, 99 \mathrm{mg} / 100 \mathrm{ml} \\
106 \mathrm{mg} / 100 \mathrm{ml}, 77 \mathrm{mg} / 100 \mathrm{ml}\end{array}$ & & \\
\hline $\begin{array}{l}\text { Time interval from initial } \\
\text { diagnosis }\end{array}$ & $3 \mathrm{mo}, 4 \frac{1}{2} \mathrm{mo}, 2 \mathrm{yr}, 2 \mathrm{yr}$ & & \\
\hline
\end{tabular}

"Transient fasting hyperglycemia $(>120 \mathrm{mg} / 100 \mathrm{ml}$ ) subsequently in four patients, FBS $100-120 \mathrm{mg} / 100 \mathrm{ml}$ in one additional patient.

†Transient fasting hyperglycemia $(>120 \mathrm{mg} / 100 \mathrm{ml})$ subsequently in one patient.

$\neq T$ ransient fasting hyperglycemia $(>120 \mathrm{mg} / 100 \mathrm{ml})$ subsequently in two patients.

We wish to report upon levels of blood glucose (venous whole blood) and plasma insulin obtained during glucose tolerance tests on 45 children, adolescents, and young adults in whom a diagnosis of latent diabetes was made. Follow-up observations over periods of 1-16 yr have been made in 35 of these individuals. These results extend observations reported previously ${ }^{6,7}$

These 45 patients have been divided arbitrarily into two groups, one consisting of 21 patients aged 9-17, and the other of 24 patients aged 18-25 yr (Table 1). All have had one or more abnormal glucose tolerance tests by our criteria, ${ }^{5}$ and all but two by the USPHS criteria. ${ }^{16}$ Thirteen of the 45 patients have had fasting hyperglycemia (FBS $>120 \mathrm{mg} / 100 \mathrm{ml}$ ) at least intermittently, and another 11 had fasting blood sugar levels between 100-120 mg/ $100 \mathrm{ml}$ (Table 1). The mean sums of increments in blood glucose over control levels for all six intervals of the glucose tolerance tests for the two groups were $619 \pm 53$ and $521 \pm 38 \mathrm{mg} / 100 \mathrm{ml}$, respectively (Table 1). In 48 healthy control subjects aged $18-25 \mathrm{yr}$, the corresponding mean sum of blood glucose increments was $130 \pm 10 \mathrm{mg} / 100 \mathrm{ml}$, which is significantly less than those of the two groups of patients $(p<0.001)$. In nonobese patients, the sums of increments in plasma insulin over control levels for all six intervals of the glucose tolerance tests were $167 \pm 31 \mu \mathrm{U} / \mathrm{ml}$ for the 14 younger patients, $214 \pm 34 \mu \mathrm{U} / \mathrm{ml}$ for 13 of the older patients, both significantly less ( $p<0.002$ and $<0.02$, respectively) than the $467 \pm 47 \mu \mathrm{U} / \mathrm{ml}$ for the control subjects 
who also were nonobese (Table 1). One nonobese, 19-yr-old patient had an insulin response of $1175 \mu \mathrm{U} / \mathrm{ml}$. His sum of increments in blood glucose was $558 \mathrm{mg} / 100 \mathrm{ml}$. Obesity was present in three of the younger and five of the older patients. A strong family history of diabetes was present in 20 of the younger and 22 of the older groups of patients.

Patients in the two groups have had follow-up tests performed during periods of up to 16 and $13 \mathrm{yr}$, respectively (Table 1). Four patients in the younger group have progressed to insulin-dependent diabetes. The ages at diagnosis were $11,14,11$, and $17 \mathrm{yr}$, and the initial fasting blood sugar levels were $125,99,106$, and $77 \mathrm{mg} / 100 \mathrm{ml}$, respectively. The initial glucose tolerance tests of these four patients did not differ significantly from the mean of the whole group. The time interval between the diagnosis of asymptomatic diabetes and progression to insulin-dependent diabetes was $3 \mathrm{mo}, 4 \frac{1}{2} \mathrm{mo}$, $2 \mathrm{yr}$, and $2 \mathrm{yr}$, respectively. The 35 patients who have had more than $1 \mathrm{yr}$ of followup have been treated either with diet alone or additionally with a sulfonylurea. It is not the purpose of this report to evaluate the effectiveness of therapy.

In the diabetic patients aged 9-17 $\mathrm{yr}$, both the fasting and the postglucose tolerance tests were significantly higher than in the control subjects aged 18-25 yr (Fig. 1).

Plasma levels of insulin for 14 of the nonobese patients of this group are shown in Fig. 1. The plasma levels of insulin in the fasting state were not different from the control group. After the administration of glucose, the diabetic group exhibited a significantly delayed and subnormal increase in plasma insulin. These results reflect determinations of plasma insulin assayed on glucose tolerance tests performed after 1961, when an immunoassay for insulin was available to us. In 5 of the 14 patients, plasma levels of insulin were not determined on the earlier glucose tolerance tests (prior to 1962) included in the mean blood glucose results of Fig. 1. However, mean levels of blood glucose during the $\mathbf{1 4}$ glucose tolerance tests on which these initial measurements of plasma insulin were made were almost identical to those of the levels of the whole group shown in Fig. 1.

Fig. 1. Initial diagnostic standard glucose tolerance tests $(1.75 \mathrm{~g}$ glucose/ $\mathrm{kg}$ ideal body weight) in mildly diabetic patients ages $9-17$ at diagnosis, and glucose tolerance tests in healthy control subjects.

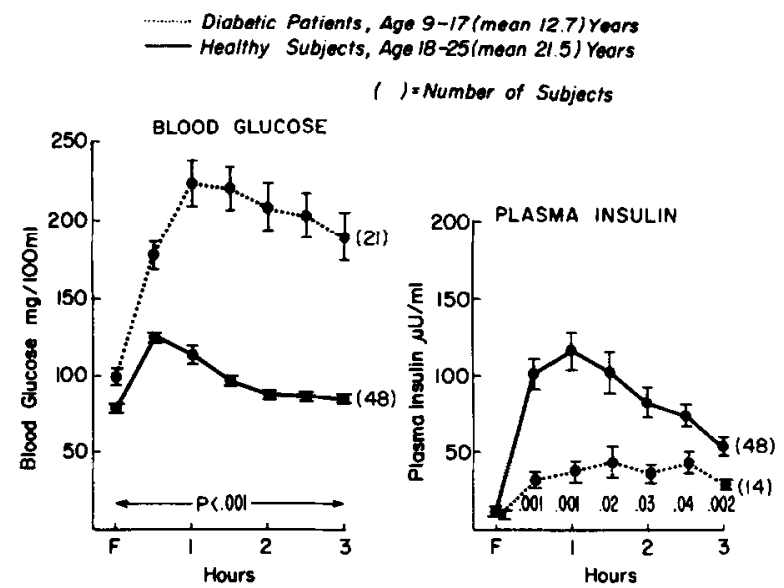




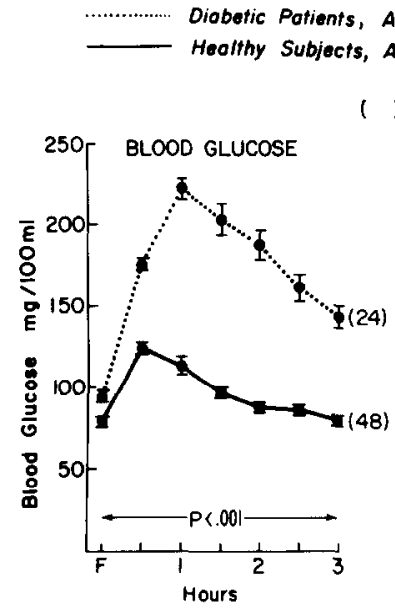

Fig. 3. Initial and last follow-up glucose tolerance tests in mildly diabetic patients, ages 9-17 at diagnosis.

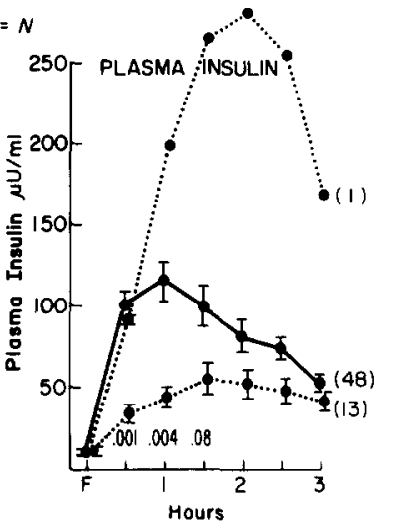

Fig. 2. Initial diagnostic standard glucose tolerance tests $(1.75 \mathrm{~g}$ glucose $/ \mathrm{kg}$ ideal body weight) in mildly diabetic patients ages 18-25 at diagnosis, and glucose tolerance tests in healthy control subjects.
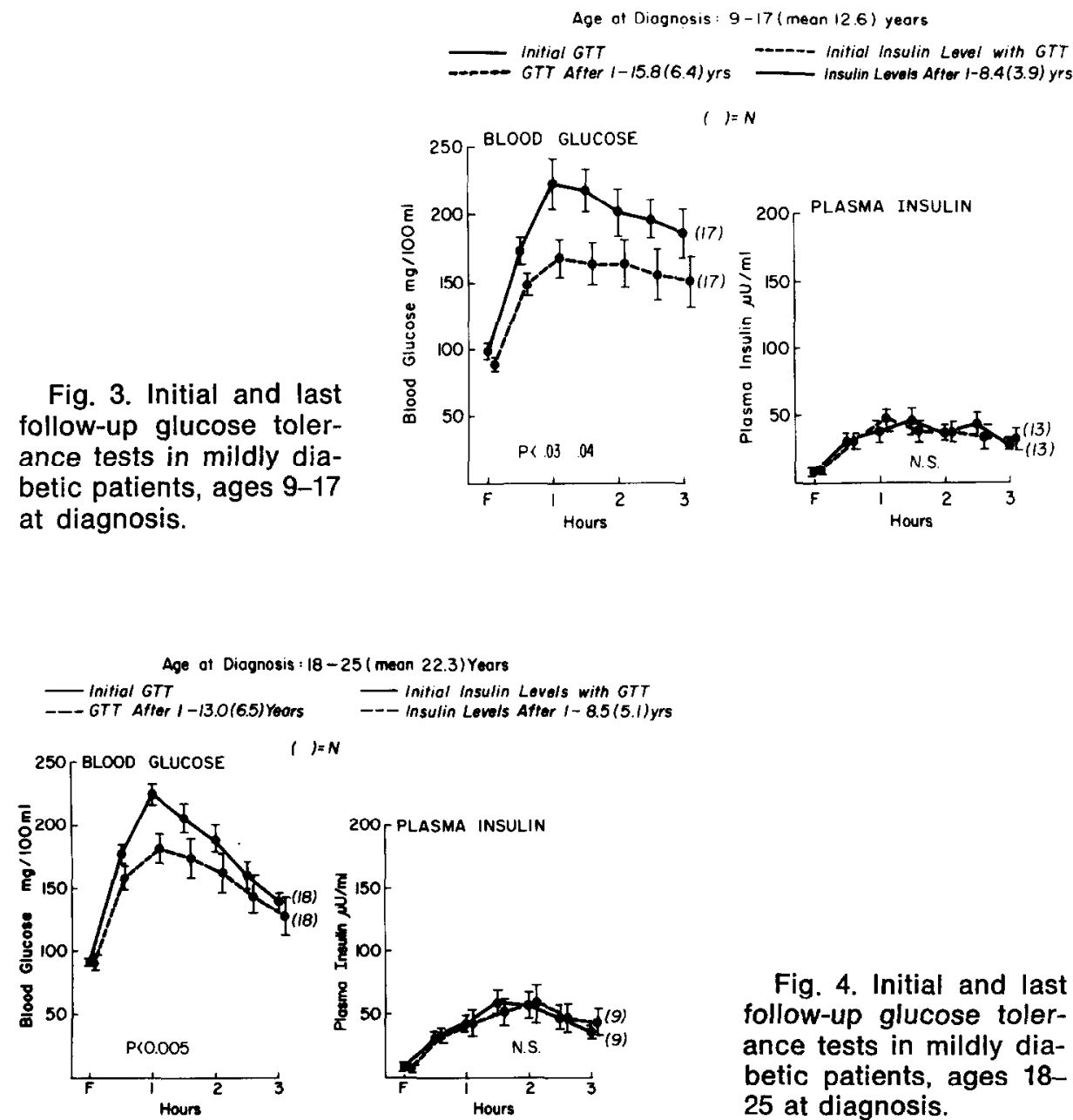

Fig. 4. Initial and last follow-up glucose tolerance tests in mildly diabetic patients, ages 1825 at diagnosis. 
The mean results of the initial diagnostic glucose tolerance tests performed in the patients aged 18-25 yr are shown in Fig. 2. Maximal increases in blood glucose were similar to those of the younger patients, but the subsequent decreases in blood glucose occurred somewhat faster. In 13 nonobese patients, there was a delayed and subnormal increase in plasma insulin after administration of glucose similar to that of the younger patients. In three of these patients, these determinations were not made on the earlier glucose tolerance tests included in the mean blood glucose results of Fig. 2. One nonobese patient showed a response, which, although delayed in reaching its peak, showed no delay at $1 / 2 \mathrm{hr}$ and was quantitatively greater than the responses of all but one of the control subjects (Fig. 2). These excessive levels of plasma insulin as measured by total immunoreactive insulin in peripheral blood were shown by Dr. Donald Steiner not to be due to proinsulin. The patient has normal sensitivity to exogenous insulin as determined by a standard insulin tolerance test. These data do not provide an explanation for the abnormal carbohydrate tolerance manifested by this patient.

In 4 of the 21 patients aged 9-17 yr at diagnosis, carbohydrate tolerance deteriorated to insulin-dependent diabetes. The other 17 patients have had follow-up tests for periods of 1-15.8. Although the abnormality in glucose tolerance has definitely progressed in two of these patients, the mean glucose tolerance of this group shows no evidence of decompensation but does show significant improrement (Fig. 3). The mean plasma insulin response during glucose tolerance tests performed 1-8.4 yr after the one on which the initial insulin determinations were made are subnormal and have shown no evidence of deterioration (Fig. 3).

Similar follow-up results were obtained for the older patients who have been retested at intervals for periods of 1-13 $\mathrm{yr}$ (Fig. 4). The mean results indicate that no significant change in glucose tolerance has occurred. There is no evidence of significant change in the subnormal insulin response to glucose after intervals of $1-8 \frac{1}{2} \mathbf{y r}$.

Considerable fluctuation in glucose tolerance may occur in some patients when the test is repeated at intervals of days, months, or years, whether such patients are untreated or treated with diet or tolbutamide. Similar fluctuations may occur in the insulin response to glucose. Although for groups of diabetic patients the magnitude of the mean insulin response to glucose is inversely related to the degree of glucose intolerance, on repetitive tests in the same patient there may be no consistent relationship between glucose tolerance and the accompanying plasma insulin response as measured by levels of insulin in peripheral blood by conventional radioimmunoassay. ${ }^{6.7}$ On repeated tests, there may be (1) the expected relationship between changes in glucose tolerance and the associated insulin response; (2) glucose tolerance may vary while the insulin response is unchanged; or (3) the insulin response may vary while glucose tolerance remains constant. Some representative examples of these findings have been reported previously. ${ }^{6.7}$ Two further illustrations of these findings are shown in Figs. 5 and 6.

Patient S.N., an 11-yr-old male, is a sibling of a girl who has ketotic-type 


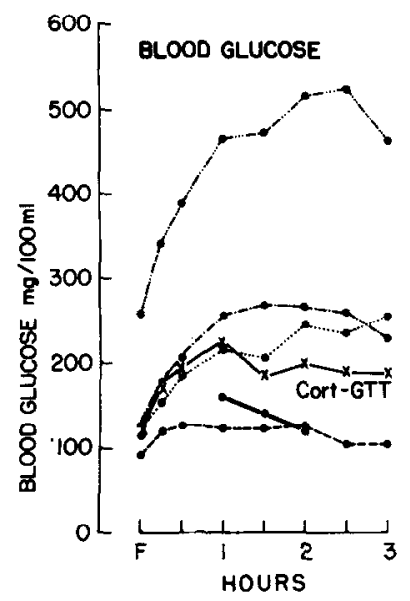

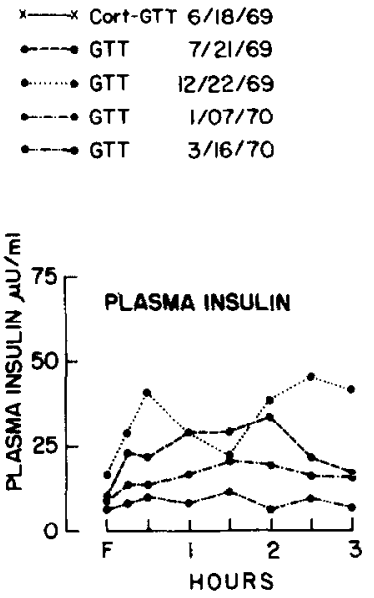

Fig. 5. Glucose tolerance tests in male patient S.N. (born 1/1/58).

diabetes and the offspring of a father with latent diabetes, which had been discovered by the performance of a routine glucose tolerance test. The boy had an abnormal cortisone glucose tolerance test in June 1969, but a normal standard glucose tolerance test in July 1969, associated with subnormal levels of plasma insulin (Fig. 5). At that time, he would have been classified as being a subclinical diabetic. In December 1969 and January 1970, asymptomatic or latent diabetes was apparent with mild fasting hyperglycemia of $125 \mathrm{mg}$ / $100 \mathrm{ml}$. The abnormal glucose tolerance test in December 1969 was associated with as rapid and somewhat greater increases in plasma insulin after glucose ingestion than when his glucose tolerance test was normal. However, in January 1970, greater glucose intolerance was associated with a delayed and lower insulin response (Fig. 5). Diet and tolbutamide therapy were then initiated. In February 1970, a 2-hr postbreakfast blood sugar level was 116 $\mathrm{mg} / 100 \mathrm{ml}$. In March 1970, overt diabetes was present with a fasting blood sugar level of $259 \mathrm{mg} / 100 \mathrm{ml}$ and a history of polydipsia and nocturia during

Fig. 6. Glucose tolerance tests in male patient S.J. (born $8 / 8 / 50$ ).
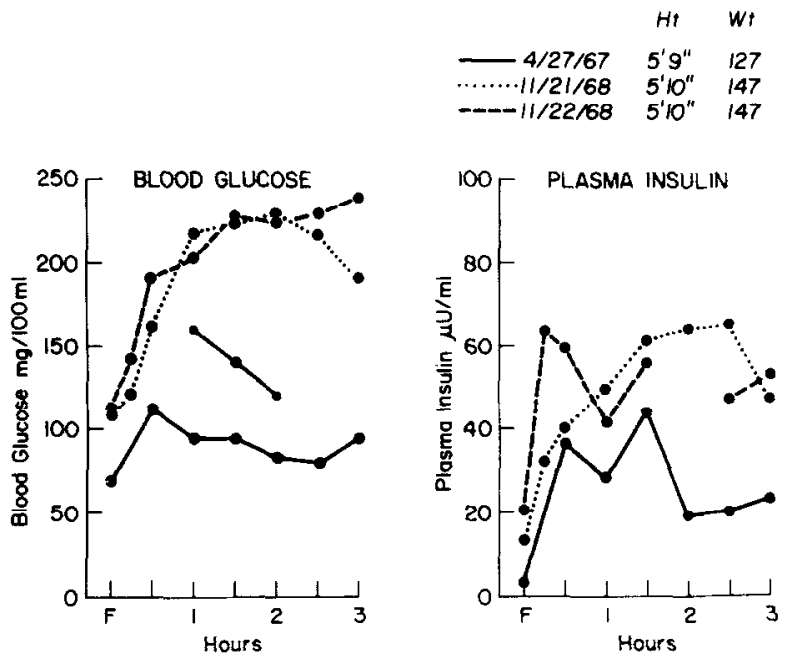
the last 5 days. At this time, there was only a negligible increment in plasma insulin in response to the administration of glucose (Fig. 5).

Patient S.J., a male whose family history of diabetes mellitus included his mother and brother, had normal glucose tolerance in April 1967 when he was $17 \mathrm{yr}$ old (Fig. 6). One and one-half yr later, two grossly abnormal glucose tolerance tests were associated with a more rapid insulin response on one occasion and a delayed one on another occasion. However, plasma levels of insulin were higher at each time period during these two tests than $1^{1 / 2} \mathrm{yr}$ earlier when he maintained normal glucose tolerance (Fig. 6). These levels of plasma insulin are lower than those of the mean of the control subjects.

\section{SUMMARY}

The results of these studies have led us to the following conclusions. (1) Although asymptomatic diabetes may progress to overt diabetes in some children, adolescents, and young adults, in the majority of such individuals studied glucose intolerance does not increase in severity over periods of up to $16 \mathrm{yr}$. (2) In the majority of these patients the mean insulin responses to glucose are delayed and subnormal, but the insulin response may not deteriorate over periods of up to $8 \mathrm{yr}$. (3) In individual patients there may be no consistent relationship between glucose tolerance and the insulin response to glucose as measured by plasma levels of insulin in peripheral blood by conventional radioimmunoassay. With the assumptions that (a) the fractional removal rate of insulin from plasma or (b) the concentrations of proinsulin or connecting peptide in plasma during glucose tolerance tests do not differ from one test to another in any one individual, our findings suggest that factors in addition to the abnormal pancreatic insulin response to glucose may determine normality or abnormality of glucose tolerance. A normal glucose tolerance test may occur in some diabetic patients in the presence of a greatly delayed and subnormal insulin response. This may occur either before or after the initial recognition of the disease. Similar findings have been reported also in prediabetic subjects ${ }^{17-20}$ and in other nondiabetic relatives of diabetic patients. ${ }^{21-23}$ (4) Since a large majority of the patients in this study have shown no significant progression of the disease, validation of diagnostic criteria for the interpretation of the glucose tolerance test need not depend on a high rate of progression to more severe hyperglycemia. (5) The slow progression of latent diabetes in many children and adolescents suggests that with early detection, time may be available for the institution of prophylactic procedures that have the potentiality of being effective.

\section{REFERENCES}

1. White, P.: Natural course and prognosis of juvenile diabetes. Diabetes 5:445, 1956.

2. Murthy, D. Y. N., Guthrie, R. A., and Womack, W. N.: Progressive decrease in insulin reserve in children with chemical diabetes. J. Pediatr. 72:567, 1968.
3. Fajans, S. S., and Conn, J. W.: Tolbutamide-induced improvement in carbohydrate tolerance of young people with mild diabetes mellitus. Diabetes $9: 83,1960$.

4. - , and -: The use of tolbutamide in the treatment of young people with mild diabetes mellitus-A progress report. 
Diabetes $11: 123$, Supplement, 1962.

5. - , and -: Prediabetes, subclinical diabetes and latent clinical diabetes: Interpretation diagnosis and treatment: In Leibel, B. S., and Wrenshall, G. S. (Eds.): On the Nature and Treatment of Diabetes. New York, Excerpta Medica, International Congress Series, 1965, p. 641.

6. -, Floyd, J. C., Jr., Conn, J. W., and Pek, S.: The course of asymptomatic diabetes of children, adolescents, and young adults. In Camerini-Davalos, R. A., and Cole, H. S. (Eds.): Early Diabetes (Supplement 1 to Advances in Metabolic Disorders). New York, Academic, 1970, p. 377.

7. -, Floyd, J. C., Jr., Pek, S., and Conn, J. W.: The course of asymptomatic diabetes in young people, as determined by levels of blood glucose and plasma insulin. Trans. Assoc. Am. Physicians 82:211, 1969.

8. Lister, J.: The clinical spectrum of juvenile diabetes. Lancet 1:386, 1966.

9. Burkeholder, J. M., Pickens, J. M., and Womack, W. N.: Oral glucose tolerance test in siblings of children with diabetes mellitus. Diabetes 16:156, 1967 .

10. Johansen, K., and Lundbaek, K.: Plasma-insulin in mild juvenile diabetes. Lancet $1: 1257,1967$.

11. Sisk, C. W.: Application of a onehour glucose tolerance test to genetic studies of diabetes in children. Lancet 1:262, 1968 .

12. Paulsen, E. P., Richenderfer, L., and Ginsbert-Fellner, F.: Plasma glucose, free fatty acids, and immunoreactive insulin in sixty-six obese children. Diabetes 17:261, 1968.

13. Chiumello, G., Del Guercio, M. J, Carnelutti, M., and Bidone, G.: Relationship between obesity, chemical diabetes and beta pancreatic function in children. Diabetes $18: 238,1969$.

14. Kahn, C. B., Soeldner, J. S., Gleason, R. E., Roias, L., Camerini-Davalos, R. A., and Marble, A.: Clinical and chemical diabetes in offspring of diabetic couples. N. Engl. J. Med. 281:343, 1969.

15. Rosenbloom, A. L.: Insulin responses of children with chemical diabetes mellitus. N. Engl. J. Med, $282: 1228,1970$.

16. Rimoin, Q. R., and Wilkerson, H. L. C. : The efficiency of screening tests for diabetes. J. Chronic Dis. 13:6, 1961.

17. Cerasi, E., and Luft, R.: Insulin re sponse to glucose infusion in diabetic and non-diabetic monozygotic twin pairs. Genetic cuntrol of insulin response? Acta Endocrinol. (Kbh) 55:330, 1967.

18. Pyke, D. A., and Taylor, K. W.: Glucose tolerance and serum insulin in unaffected identical twins of diabetics. Br. Med. J. $4: 21,1967$.

19. Colwell, J. A., and Lein, A.: Diminished insulin responses to hyparglycemia in prediabetes and diabetes. Diabetes 16:560, 1967.

20. Rojas, L., Soeldner, J. S., Gleason, R. E., Kahn, C. B., and Marble, A.: Offspring of two diabetic parents: Differential serum insulin responses to intravenous glucose and tolbutamide. I. Clin. Endocrinol. Metab. 29:1569, 1969.

21. Fajans, S. S., Floyd, I. C., Ir., Conn, J. W. Pek, S., Rull, J., and Knopf, R. F.: Plasma insulin responses to ingested glucose and to infused amino acids in subclinical diabetes and prediabetes. New York, Excerpta Medica, International Congress Series No. 172, 1969, p. 172.

22. Floyd, J. C., Jr., Fajans, S. S., Conn, J. W., Thiffault, C., Knopf, R. F., and Guntsche, E.: Secretion of insulin induced by amino acids and glucose in diabetes mellitus. J. Clin. Endocrinol. Metab. 28:266, 1968.

23. Kull, J. A., Conn, J. W., Floyd, J. C., Jr., and Fajans, S. S.: Levels of plasma insulin during cortisone glucose tolerance tests in "nondiabetic" relatives of diabetic patients. Implications of diminished insulin secretory reserve in subclinical diabetes. Diabetes $19: 1,1970$.

24. New York, Excerpta Medica, International Congress Series No. 238, 1971, p. 456.

\section{Discussion}

Dr. Guthrie: I am a little concerned about the norms that you showed for insulin. These were older patients. Just looking at a few of the figures-your 30-min value, for instance, was around $100 \mu \mathrm{U} / \mathrm{ml}$-then you compared the children to this. By our norms in children the means are much lower than that. Our means at $30 \mathrm{~min}$, for instance, are 